\title{
Safety monitoring of herbal medicines in Nigeria: worrying state of pharmacovigilance system based on WHO core pharmacovigilance indicators
}

\author{
Sulayman Tunde Balogun ${ }^{1^{\circledR}}$, Kenneth Okwong Okon ${ }^{(\mathbb{D}}$, Ayodele Oluwasoji Akanmu ${ }^{\mathbb{D}}$, Leonard Mela Paul ${ }^{1}$, \\ Olufunke Adebola Sodipo ${ }^{1(\mathbb{D}}$ \\ ${ }^{1}$ Department of Clinical Pharmacology and Therapeutics, Faculty of Basic Clinical Sciences, College of Medical Sciences, University of Maiduguri, \\ Maiduguri, Nigeria \\ ${ }^{2}$ Department of Medical Microbiology, Federal Medical Centre, Makurdi, Nigeria
}

\section{A R T I C L E IN F O}

Article Type:

Original Article

\section{Article History:}

Received: 30 May 2020

Accepted: 20 August 2020

\section{Keywords:}

Adverse reactions

Herbal medicines

Nigeria

Phytovigilance

Safety

\begin{abstract}
A B S T R A C T
Introduction: Herbal medicines (HMs) have shown therapeutic and toxicological potentials. Thus, the WHO expanded the pharmacovigilance (PVG) scope to include HMs. This study appraised the state of PVG system in Nigeria for the safety monitoring of HMs using WHO core PVG indicators.

Methods: Between January and June 2019, 39 PVG experts were requested to independently appraise the PVG system in Nigeria for safety monitoring of HMs using WHO PVG core structural (CSIs), process (CPIs) and outcome (COIs) indicators. The 27 indicators (CSIs $=10$, CPIs $=9$ and COIs $=8$ ) were scored 3, 2, 1 and 0 for adequate, fairly adequate, inadequate and uncertain states, respectively. CSIs index (CSII) was determined by dividing the summation of CSIs mean score by total obtainable score (30) and expressed in percentage. This was applied to CPIs and COIs to obtain CPIs index (CPII) and COIs index (COII), respectively.

Results: The mean \pm standard deviation (SD) of participants' age was $43.6 \pm 10.3$ years with mean \pm SD work experience of $15.3 \pm 9.3$ years. Majority had doctoral degree (35.9\%; 14/39; $\mathrm{P}$ $>0.05)$ and were medical doctors $(28.2 \% ; 11 / 39 ; P>0.05)$. Twelve of the 27 indicators scored at least 2.0 and CSIs, CPIs, and COIs accounted for $75.0 \%(9 / 12), 0.0 \%(0 / 12)$ and $25.0 \%(3 / 12)$, respectively $(P<0.05)$. The total mean score was $27.3 \pm 0.2$ for CSIs as against $8.0 \pm 0.3$ for CPIs and $11.2 \pm 0.4$ for COIs $(P<0.05)$. The CSII, CPII and COII were $91.0 \% ; 29.6 \%$ and $46.7 \%$, respectively $(P<0.05)$.

Conclusion: Most of the structural elements are in place for safety monitoring of HMs in Nigeria. However, the process and outcome of PVG indicate inadequate state. Thus, deliberate efforts are required to ensure realization of PVG objectives.
\end{abstract}

Implication for health policy/practice/research/medical education:

The study's findings and recommendations could be used to make policies on safe and effective uses of herbal medicines. It will ensure effective monitoring of the safety of herbal medicines, reduce the extent of the adverse reactions and improve treatment outcomes. In addition, it provides evidence-based baseline data for future research.

Please cite this paper as: Balogun ST, Okon KO, Akanmu AO, Paul LM, Sodipo OA. Safety monitoring of herbal medicines in Nigeria: worrying state of pharmacovigilance system based on WHO core pharmacovigilance indicators. J Herbmed Pharmacol. 2021;10(2):202-208. doi: 10.34172/jhp.2021.22

\section{Introduction}

Traditional medicine is increasingly gaining global recognition among rural and urban populations especially in Africa, Asia and Latin America (1). It is an integral part of the health care system in these regions, where an estimated $80 \%$ of the population considered traditional medicine as a source of primary health care (2). Traditional medicine practitioners treat various illnesses using herbal medicines (HMs), which are mainly prepared from medicinal plants and other natural substances $(1,3)$. Previous reports have provided comprehensive lists of medicinal plants used as HMs (3-5) and the preparation techniques used by the traditional practitioners (6). The efficacies of HMs have been demonstrated in the treatment of various infectious 
and non-infectious diseases such as malaria (7), bacterial infections (8), diabetes mellitus (9), and hypertension (10), among others. These therapeutic activities are attributable to the presence of pharmacologically active phytochemicals in plants (4). The increased popularity of HMs in Africa is due to several factors, including abundance of medicinal plants, tradition, drug resistance, cost and side effects of orthodox drugs and the perceived efficacy and safety of HMs (11).

Despite the therapeutic effects of HMs, they can potentially induce toxicological effects (12), which are also associated with the active phytochemical constituents. For instance, saponins are known to have bitter taste, haemolytic, cytotoxic and antinutritional effects (13), while alkaloids may possess hepatoxic, cardiotoxic, and neurotoxic properties (14). In addition, contaminants such as microbes and heavy metals may be mistakenly introduced into the HMs during preparation $(15,16)$. Previous studies have reported adverse effects resulting from irrational consumption of HMs (17-19). This emphasizes the need for rigorous safety monitoring of HMs similar to what is obtainable with orthodox drugs. Thus, the WHO recommends safety as a fundamental principle in providing HMs for health care, and as a vital element of quality control (20).

Pharmacovigilance (PVG), the science of safety monitoring, initially focused on conventional medicines but the product spectrum has expanded to include HMs (21) due to concern of HMs safety (1). The WHO established guidelines for safety monitoring of HMs with provisions for reporting process, signal detection, causality assessment, scope of the herbal products, extent of what to be reported and probable challenges (20). In order to ascertain the functionality of PVG system in different settings, WHO developed PVG indicators that are used to measure the preparedness of the system for effective safety monitoring of drugs, HMs and other relevant products. The indicators provide scientific information on baseline situation and progress in systems and the assessment of services and interventions. They are categorized into core and complementary indicators with each category comprising structural, process, and outcome core or complementary indicators. The core indicators are the elements that are highly relevant and vital to achieving the objectives of PVG (21).

In Nigeria, the National Pharmacovigilance Centre (NPC), a unit of the National Food and Drug Administration and Control (NAFDAC) is statutorily responsible for PVG activities (22). NPC has conducted several safety monitoring activities including cohort event monitoring of drugs (23), however, the efforts on HMs are considered inadequate. Similarly, few studies have evaluated the PVG system in Nigeria using the WHO indicators with a focus on conventional medicines (24). Thus, the present study assessed the state of preparedness of PVG system in Nigeria for safety monitoring of HMs using WHO core PVG indicators.

\section{Materials and Methods}

The study was conducted at the Department of Clinical Pharmacology and Therapeutics, Faculty of Basic Clinical Sciences, College of Medical Sciences, University of Maiduguri, Maiduguri, Nigeria, between January and June 2019 with participants enrolled across the country. Sixty individuals with expertise in PVG were invited to participate in the study. However, 39 invitees consented and enrolled in the study. The inclusion criteria were: (i) expertise in PVG, (ii) relevant professional background, (iii) residence in Nigeria, (iv) current involvement in PVG activities such as teaching, practice and research, and $(v)$ informed consent. Expertise in PVG was operationally defined as individuals with relevant professional backgrounds, involving in PVG activities such as teaching, research and practice.

The data were collected using data collection form for PVG indicators as described by WHO (21) with a minor modification. The form was used to obtain data on the demographic characteristics of the participants (Section A) and the state of PVG system in Nigeria for safety monitoring of HMs based on core structural indicators (CSIs) [Section B], core process indicators (CPIs) [Section C] and core outcome indicators (COIs) [Section D]. CSIs assessed the availability of essential basic infrastructure, systems, relevant policies, funds, and regulatory framework for safety monitoring of HMs using ten structural indicators. CPIs evaluated the level of HMs-related PVG activities such as collection, collation, analysis, and evaluation of adverse reactions due to HMs using nine process indicators. COIs measured the extent of realization of PVG objectives using the eight elements of outcome indicators (21). The participants were requested to independently and objectively score the state of PVG system in Nigeria in respect to safety monitoring of HMs based on CSIs, CPIs, and COIs on the scales of 3, 2, 1, and 0 for adequate, fairly adequate, inadequate, and uncertain states, respectively. Then, the CSIs index (CSII), CPIs index (CPII) and COIs index (COII) were determined using the formula below:

CSII / CPII / COII $(\%)=\frac{\text { Mean Score }(\text { CSIs / CPIs / COIs })}{\text { Total Obtainable Score }(C S I s / C P I s / C O I s)}$

The data obtained were analyzed using Statistical Package for Social Science (SPSS) window version 16.0. The data were presented as mean \pm standard deviation (SD) and percentage where applicable. The means of the CSIs, CPIs, and COIs were compared using analysis of variance (ANOVA) and CSII, CPII, and COII were compared using chi-square. Significance difference was inferred at $P<0.05$. 


\section{Results}

Table 1 presents the characteristics of the 39 experts who participated in the study. The mean \pm SD age of the participants was $43.6 \pm 10.3$ years, and mean \pm SD work experience was $15.3 \pm 9.3$ years. The majority of the participants had a doctoral degree $(35.9 \% ; P>0.05)$ as the highest qualification and were medical doctors $(28.2 \% ; P$ $>0.05$ ) by profession. Collectively, 12 of the 27 indicators scored at least 2.0 and CSIs, CPIs and COIs accounted for $75.0 \%(9 / 12), 0.0 \%(0 / 12)$ and $25.0 \%(3 / 12)$, respectively $(P<0.05)$ as shown in Figure 1. Out of the ten elements of CSIs evaluated, nine indicators had a mean score above 2.0 with seven indicators having the highest obtainable score of 3.0. However, CSIs- 5 recorded a mean score \pm SD of $1.7 \pm 0.8$ (Table 2). None of the nine elements of CPIs assessed had a mean score upto 2.0 with CPIs- 8 having the highest mean score \pm SD of $1.2 \pm 0.4$ while CPIs1 and CPIs- 4 with the least score of $0.7 \pm 0.4$ (Table 3). Similarly, the perception of the state of PVG system in respect of HMs based on CPIs was generally poor. Only three of the indicators scored at least 2.0. COIs- 6 and COIs-7 received the highest mean score of $2.1 \pm 0.6$ while COIs-1, COIs- 3 , COIs- 4 , and COIs- 5 had the least mean score of $0.9 \pm 0.3$ (Table 4 ). In addition, the perception of the state of PVG system in Nigeria for safety monitoring of HMs was compared using CSII, CPII, and COII. The results showed that CSII had the highest index of $91.0 \%$ $(P<0.05)$, indicating the adequate state of the system for

Table 1. Characteristics of the participants

\begin{tabular}{|c|c|c|c|}
\hline Variable & Category & Value (\%) & $P$ value \\
\hline Number enrolled & - & 39 (100.0) & - \\
\hline \multirow{2}{*}{ Age $(y)$} & Mean \pm SD & $43.6 \pm 10.3$ & \multirow{2}{*}{-} \\
\hline & Range & $28.0-61.0$ & \\
\hline \multirow{2}{*}{ Sex } & Female & $15(38.5)$ & \multirow{2}{*}{$<0.05$} \\
\hline & Male & $24(61.5)$ & \\
\hline \multirow{2}{*}{ Work experience (y) } & Mean \pm SD & $15.3 \pm 9.3$ & \multirow{2}{*}{-} \\
\hline & Range & $2.0-33.0$ & \\
\hline \multirow{4}{*}{ Highest qualification } & Doctoral degree & $14(35.9)$ & \multirow{4}{*}{$>0.05$} \\
\hline & PG Fellowship & $8(20.5)$ & \\
\hline & Masters degree & $8(20.5)$ & \\
\hline & Bachelor degree & $9(23.1)$ & \\
\hline \multirow{6}{*}{ Profession } & Dental doctor & $4(10.3)$ & \multirow{6}{*}{$>0.05$} \\
\hline & Medical doctor & $11(28.2)$ & \\
\hline & Nurse & $5(12.8)$ & \\
\hline & Pharmacist & $9(23.1)$ & \\
\hline & Veterinarian & $4(10.3)$ & \\
\hline & Others & $6(15.4)$ & \\
\hline \multirow{2}{*}{$\begin{array}{l}\text { Geographical } \\
\text { distribution }\end{array}$} & Northern Nigeria & $18(46.2)$ & \multirow{2}{*}{$>0.05$} \\
\hline & Southern Nigeria & $21(53.8)$ & \\
\hline
\end{tabular}

PG, postgraduate; SD, standard deviation.

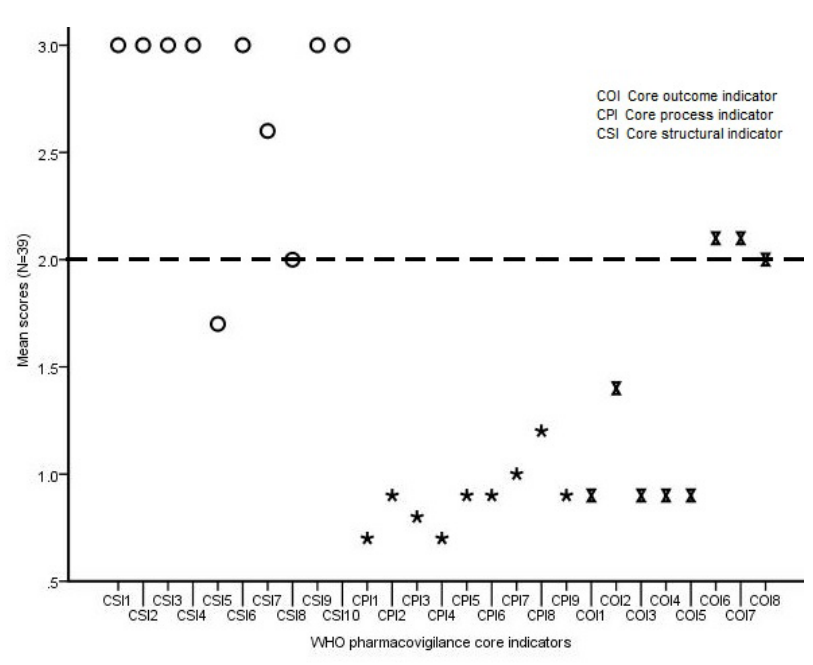

Figure 1. The WHO PVG core indicators scores for HMs safety monitoring in Nigeria (dotted line represents minimum pass score).

safety monitoring of HMs based on structural elements (Figure 2).

\section{Discussion}

The WHO has established guidelines for safety monitoring of HMs in PVG systems (20) and developed PVG indicators for assessing the state of the PVG systems for effective safety monitoring of medical devices, prophylactic and therapeutic agents including HMs (21). In Nigeria, previous studies have identified some challenges in reporting adverse reactions due to HMs (17) and the state of PVG system (24) in some parts of the country. Thus, the present study investigated the state of PVG system with respect to safety monitoring of HMs in Nigeria using the WHO core PVG indicators - CSIs, CPIs, and COIs.

CSIs are used to evaluate availability and adequacy of basic infrastructure, systems, and policies required for the optimum discharge of PVG activities in a setting (20). With the CSII of 91\%, the present finding suggests that PVG system in Nigeria has infrastructure, system, policies, and regulatory bodies adequate for safety monitoring of HMs used in Nigeria. This is evident by existence of NPC, NAFDAC, yellow form (22), National Drug Policy in Nigeria (25), National PVG Policy and Implementation Framework (22), and annual budgetary allocations by the Government (26). Previous studies have also demonstrated adequacy of PVG system in Nigeria considering the structural indicators (24). However, the low score for CSIs-5 indicates that available human resources may not be adequate to operate the available infrastructure; hence, the need for urgent training of individuals to complement the existing workforce. This is in accordance with studies within and outside Nigeria that have reported inadequacy of experienced professionals to ensure effective implementation of PVG activities (27- 
Table 2. The state of pharmacovigilance system in Nigeria for safety monitoring of herbal medicines based on WHO core structural indicators

\begin{tabular}{llcc}
\hline CSIs & Description & Score Obtained* & Score Obtainable \\
\hline CSIs-1 & Existence of pharmacovigilance centre, department, unit with a standard accommodation & $3.0 \pm 0.0$ & 3.0 \\
CSIs-2 & Existence of statutory provision (national policy and legislation) for pharmacovigilance & $3.0 \pm 0.0$ & 3.0 \\
CSIs-3 & Existence of medicines (herbal) regulatory authority or agency & $3.0 \pm 0.0$ & 3.0 \\
CSIs-4 & Existence of regular financial provision (e.g. statutory budget) for the pharmacovigilance centre & $3.0 \pm 0.0$ & 3.0 \\
CSIs-5 & Adequate human resources for the pharmacovigilanve centre & $1.7 \pm 0.8$ & 3.0 \\
CSIs-6 & Existence of standard adverse drug reaction reporting form & $3.0 \pm 0.0$ & 3.0 \\
CSIs-7 & Process for collection, recording and analysis of adverse drug reaction reports & $2.6 \pm 0.5$ & 3.0 \\
CSIs-8 & $\begin{array}{l}\text { Incorporation of pharmacovigilance into national curriculum of the various health-care } \\
\text { professions }\end{array}$ & $2.0 \pm 0.8$ & 3.0 \\
CSIs-9 & $\begin{array}{l}\text { Existence of newsletter, information bulletin or website for dissemination of pharmacovigialnce } \\
\text { information }\end{array}$ & $3.0 \pm 0.0$ & 3.0 \\
CSIs-10 & $\begin{array}{l}\text { Existence of national adverse drug reaction or pharmacovigilance advisory committee or an } \\
\text { expert committee in the setting capable of providing advice on medicine safety }\end{array}$ & $3.0 \pm 0.0$ & 3.0 \\
\hline & Total & $27.3 \pm 0.2$ & 30.0 \\
\hline
\end{tabular}

CSIs, core structural indicators.

$*$ Values are mean \pm standard deviation.

Table 3. The state of pharmacovigilance system in Nigeria for safety monitoring of herbal medicines based on WHO core process indicators

\begin{tabular}{llcc}
\hline CPIs & Description & *Score Obtained & Score Obtainable \\
\hline CPIs-1 & Total number of herbal medicine adverse drug reactions reports received in 2018 & $0.7 \pm 0.4$ & 3.0 \\
CPIs-2 & Current herbal medicine adverse drug reactions reports in the national, regional or local database & $0.9 \pm 0.4$ & 3.0 \\
CPIs-3 & Percentage of total annual reports acknowledged & $0.8 \pm 0.4$ & 3.0 \\
CPIs-4 & Percentage of total annual reports subjected to causality assessment in 2018 & $0.7 \pm 0.4$ & 3.0 \\
CPIs-5 & Percentage of total annual reports completed and submitted to National Pharmacovigilance & $0.9 \pm 0.3$ & 3.0 \\
CPIs-6 & Pentre in 2018 & $0.9 \pm 0.3$ & 3.0 \\
CPIs-7 & Percentage of total reports due to ineffectiveness of herbal medicines reported in 2018 & $1.0 \pm 0.2$ & 3.0 \\
CPIs-8 & Percentage of registered pharmaceutical companies having functional pharmacovigilance system & $1.2 \pm 0.4$ & 3.0 \\
CPIs-9 & Number of active surveillance activities initiated, ongoing or completed between 2014-2018 & $0.9 \pm 0.3$ & 3.0 \\
- & Total & $8.0 \pm 0.3$ & 27.0 \\
\hline
\end{tabular}

CPIs, core process indicators.

* Values are mean \pm standard deviation.

Table 4. The state of pharmacovigilance system in Nigeria for safety monitoring of herbal medicines based on WHO core outcome indicators

\begin{tabular}{|c|c|c|c|}
\hline COls & Description & Score Obtained* & Score Obtainable \\
\hline COls-1 & $\begin{array}{l}\text { Number of herbal medicine-related signals detected in } 2014-2018 \text { by National } \\
\text { Pharmacovigilance Centre }\end{array}$ & $0.9 \pm 0.3$ & 3.0 \\
\hline COls-2 & Number of regulatory actions taken in 2018 concerning herbal medicine & $1.4 \pm 0.5$ & 3.0 \\
\hline COls-3 & Number of herbal medicine-related hospital admissions/1000 admissions & $0.9 \pm 0.3$ & 3.0 \\
\hline COls-4 & Number of herbal medicine-related deaths/1000 persons served by the hospital/year & $0.9 \pm 0.3$ & 3.0 \\
\hline COls-5 & Number of herbal medicine-related deaths $/ 100,000$ persons in the population & $0.9 \pm 0.3$ & 3.0 \\
\hline COls-6 & Average cost of treatment of herbal medicine-related illness & $2.1 \pm 0.6$ & 3.0 \\
\hline COls-7 & Average duration (days) of herbal medicine-related extention of hospital stay & $2.1 \pm 0.6$ & 3.0 \\
\hline COls-8 & Average cost of herbal medicine-related hospitalization & $2.0 \pm 0.6$ & 3.0 \\
\hline- & Total & $11.2 \pm 0.4$ & 24.0 \\
\hline
\end{tabular}

COls, core outcome indicators.

* Values are mean \pm standard deviation. 


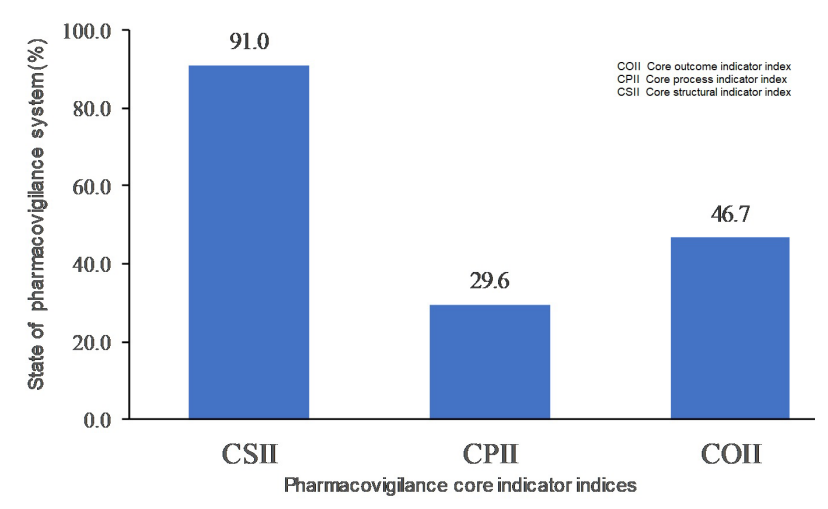

Figure 2. CSII, CPII and COII of PVG system for HMs safety monitoring in Nigeria $(P<0.05)$.

30). Also noteworthy is the moderate score obtained by CSIs- 8 that assesses the extent of incorporation of PVG into national educational curricula. Thus, the National Universities Commission in Nigeria is hereby urged to review the undergraduate curricula of Medicine, Dentistry, Pharmacy, Pharmacology, Veterinary Medicine and other relevant disciplines to accommodate PVG.

Another important indicator is CPIs, which measures the level of PVG activities, including collection, collation, analysis, and evaluation of adverse drug reactions (21). Based on process indicators, the PVG system appears not adequately prepared for the safety monitoring of HMs in Nigeria. Specifically, the records of HMs adverse reactions, ineffectiveness, and medication errors reported in 2018 and the causality assessment and active surveillance related to HMs conducted in 2018 were grossly insufficient. However, these are not surprising because previous studies have shown poor reportage of harmful effects of HMs $(17,31)$ and orthodox drugs $(28,30)$ in Africa even among the health care professionals. This could be partly due to the perceived general safety of HMs (11) and unawareness of the inclusion of HMs among the products covered by PVG (unpublished data). Similarly, records have shown that most of the active surveillance of safety monitoring conducted in $2014-2018$ focused on antimalarial drugs $(23,24)$. Thus, the NPC needs to improve on her activities such as (i) active surveillance of efficacy and safety of HMs, (ii) causality assessment of HMs-related reports, and (iii) awareness campaign and education of the public and relevant professionals on the need to report adverse reactions due to HMs.

The outcome or impact indicators, COIs, assess actualization of PVG objectives, which primarily ensure the patients' safety (21). The findings from the present study suggest that the PVG system in Nigeria is marginally prepared for safety monitoring of HMs as indicated by the COII of $46.7 \%$. There is dearth of adequate data on cost of treating adverse reactions due to HMs, number of admitted patients, and duration of hospitalization in line with a previous study that has reported inadequate data for outcome or impact indicators analysis (24). This may be a reflection of the poor HMs-related PVG activities conducted in the last few years as earlier discussed. Thus, the NPC should also direct adequate resources towards detecting HMs-related signals, taking appropriate regulatory actions when necessary, and collecting data on number of admission, cost of treatment of adverse reactions, duration of hospitalization, and mortality resulting from HMs consumption. These could be achieved through adequate training of health care professionals and traditional practitioners on scope and methods of PVG, and public campaign on the need to report adverse reactions following self-medication with HMs.

\section{Conclusion}

It could be concluded that the state of PVG system in Nigeria is adequate for safety monitoring of HMs considering the existence of basic infrastructure, national drug policy, PVG policy, and financial provision, among other structural indicators. However, deliberate systematic efforts targeting process and outcome indicators are required to position the PVG system in a better operational state for optimum outcomes. The present findings provide baseline scientific data on the state of PVG system and could contribute to the effective use and safety monitoring of HMs.

\section{Acknowledgements}

The authors acknowledged all the participants for their time and for sharing their expert opinion on PVG system in Nigeria.

\section{Authors' contributions}

STB and KOO conceptualized and designed the study. STB, $\mathrm{KOO}$ and AOA enrolled the participants and collected the data. STB and LMP analyzed the data. STB wrote the first draft of the manuscript. KOO, AOA, LMP and OAS made significant inputs into the final version of the manuscript. OAS provided important advice at all stages of the study. All authors read the final version of the manuscript and confirmed it for publication.

\section{Conflict of interests}

The authors declare no conflict of interests.

\section{Ethical considerations}

Not applicable.

\section{Funding/Support}

The authors did not receive financial support for the study.

\section{References}

1. World Health Organization (WHO). WHO Traditional 
Medicine Strategy 2014-2023. Geneva: WHO; 2013. Available from: https://apps.who.int/iris/bitstream/ handle/10665/92455/9789241506090_eng.pdf;jsessionid= 56D02174E5E757FDF3231ABBB7BF1B3D? sequence $=1$. Accessed May 8, 2020.

2. World Health Organization (WHO). The Africa Health Monitor. WHO; 2010. Available from: https:// reliefweb.int/sites/reliefweb.int/files/resources/FCC3BB0257168C448525779000718FB3-who-ahm-specialissue-aug2010.pdf. Accessed May 8, 2020.

3. Kahumba J, Rasamiravaka T, Okusa PN, Bakari A, Bizumukama L, Kalonji JB, et al. Traditional African medicine: from ancestral knowledge to a modern integrated future. Science. 2015;350(6262):S61-3.

4. World Health Organization (WHO). WHO Monographs on Selected Medicinal Plants (Volume 4). WHO; 2009. Available from: https://www.who.int/medicines/areas/ traditional/SelectMonoVol4.pdf. Accessed on October 20, 2019.

5. Abd El-Ghani MM. Traditional medicinal plants of Nigeria: an overview. Agric Biol J N Am. 2016;7(5):220-7.

6. Sheridan H, Kopp B, Krenn L, Guo D, Sendker J. Traditional Chinese herbal medicine preparation: invoking the butterfly effect.Science.2015;350(6262):S64-6.

7. Okello D, Kang Y. Exploring antimalarial herbal plants across communities in Uganda based on electronic data. Evid Based Complement Alternat Med. 2019;2019:3057180. doi: 10.1155/2019/3057180.

8. Balogun ST, Nwabugwu AO, Akanmu AO, Jibrin J, Gamache S. Antipseudomonal activities of aqueous and methanolic peel extracts of Carica papaya L. (Pawpaw) unripe fruits. IOSR J Pharm Biol Sci. 2016;11(6):38-41. doi: 10.9790/3008-1106063841.

9. Oguntibeju OO. Hypoglycaemic and anti-diabetic activity of selected African medicinal plants. Int J Physiol Pathophysiol Pharmacol. 2019;11(6):224-37.

10. Samaha AA, Fawaz M, Salami A, Baydoun S, Eid AH. Antihypertensive indigenous lebanese plants: ethnopharmacology and a clinical trial. Biomolecules. 2019;9(7). doi: 10.3390/biom9070292.

11. Ekor M. The growing use of herbal medicines: issues relating to adverse reactions and challenges in monitoring safety. Front Pharmacol. 2014;4:177. doi: 10.3389/ fphar.2013.00177.

12. Kaur J, Kaur S, Mahajan A. Herbal medicines: possible risks and benefits. Am J Phytomed Clin Ther. 2013;1(2):226-39.

13. El Hazzam K, Hafsa J, Sobeh M, Mhada M, Taourirte M, El Kacimi K, et al. An insight into saponins from Quinoa (Chenopodium quinoa Willd): a review. Molecules. 2020;25(5). doi: 10.3390/molecules25051059.

14. Diaz GJ. Toxicosis by plant alkaloids in humans and animals in Colombia. Toxins (Basel). 2015;7(12):5408-16. doi: $10.3390 /$ toxins7124892.

15. Crighton E, Coghlan ML, Farrington R, Hoban CL, Power MWP, Nash C, et al. Toxicological screening and DNA sequencing detects contamination and adulteration in regulated herbal medicines and supplements for diet, weight loss and cardiovascular health. J Pharm Biomed Anal. 2019;176:112834. doi: 10.1016/j.jpba.2019.112834. 16. Hoban CL, Musgrave IF, Byard RW, Nash C, Farrington
R, Maker G, et al. Combined liquid chromatographymass spectrometry and next-generation DNA sequencing detection of adulterants and contaminants in analgesic and anti-inflammatory herbal medicines. Pharmaceut Med. 2020;34(1):49-61. doi: 10.1007/s40290-019-00314-y.

17. Awodele O, Daniel A, Popoola TD, Salami EF. A study on pharmacovigilance of herbal medicines in Lagos West Senatorial District, Nigeria. Int J Risk Saf Med. 2013;25(4):205-17. doi: 10.3233/jrs-130604.

18. Kamsu-Foguem B, Foguem C. Adverse drug reactions in some African herbal medicine: literature review and stakeholders' interview. Integr Med Res. 2014;3(3):126-32. doi: 10.1016/j.imr.2014.05.001.

19. Moreira DL, Teixeira SS, Monteiro MHD, De-Oliveira ACAX, Paumgartten FJR. Traditional use and safety of herbal medicines. Rev Bras Farmacogn. 2014;24(2):248-57. doi: 10.1016/j.bjp.2014.03.006.

20. World Health Organization (WHO). WHO Guidelines on SafetyMonitoring of Herbal Medicines in Pharmacovigilance Systems. Geneva: WHO; 2004. Available from: https://doi. org/http://www.regione.emiliaromagna.it/agenziasan/ $\mathrm{mnc} / \mathrm{pdf} /$ documenti/oms/who_guid_pharmacovig.pdf. Accessed August 17, 2018.

21. World Health Organization (WHO). WHO Pharmacovigilance Indicators: A Practical Manual for the Assessment of Pharmacovigilance Systems. Geneva: WHO; 2015. Available from: https://www.who.int/medicines/ areas/quality_safety/safety_efficacy/EMP_PV_Indicators_ web_ready_v2.pdf. Accessed September 2, 2018.

22. National Food and Drug Administration and Control (NAFDAC). National policy and implementation guideline on pharmacovigilance. 2011. Available from: https://drive.google.com/file/ d/0B1DAmtM1BcbMX3lqemU4bEtxVW8/view. Accessed May 10, 2020.

23. Bassi PU, Osakwe AI, Suku C, Kalat M, Elagbaje C, Isah A, et al. Cohort event monitoring of patients treated for uncomplicated malaria with artemisinin-based combination therapies in selected hospitals and community pharmacies in Nigeria. Niger Postgrad Med J. 2016;23(4):172-81. doi: 10.4103/1117-1936.196246.

24. Opadeyi AO, Fourrier-Réglat A, Isah AO. Assessment of the state of pharmacovigilance in the South-South zone of Nigeria using WHO pharmacovigilance indicators. BMC Pharmacol Toxicol. 2018;19(1):27. doi: 10.1186/s40360018-0217-2.

25. Federal Ministry of Health (FMOH). National drug policy in Nigeria (First revision). 2005. Available from: http:// collections.infocollections.org/whocountry/en/d/Js6865e. Accessed May 10, 2020.

26. Federal Government of Nigeria (FGN). 2019 appropriation bill. 2019. Available from: https://www.budgetoffice.gov.ng/ index.php/2019-budget. Accessed May 10, 2020.

27. Okechukwu RC, Odinduka SO, Ele GN, Okonta MJ. Awareness, attitude, and practice of pharmacovigilance among health care professionals in Nigeria: survey in a teaching hospital. Int J Hosp Res. 2013;2(3):99-108.

28. Maigetter K, Pollock AM, Kadam A, Ward K, Weiss MG. Pharmacovigilance in India, Uganda and South Africa with reference to WHO's minimum requirements. Int J 
Health Policy Manag. 2015;4(5):295-305. doi: 10.15171/ ijhpm.2015.55.

29. Alsaleh FM, Alzaid SW, Abahussain EA, Bayoud T, Lemay J. Knowledge, attitude and practices of pharmacovigilance and adverse drug reaction reporting among pharmacists working in secondary and tertiary governmental hospitals in Kuwait. Saudi Pharm J. 2017;25(6):830-7. doi: 10.1016/j. jsps.2016.12.004.

30. Opadeyi AO, Fourrier-Réglat A, Isah AO. Educational intervention to improve the knowledge, attitude and practice of healthcare professionals regarding pharmacovigilance in South-South Nigeria. Ther Adv Drug Saf. 2019;10:2042098618816279. doi: 10.1177/2042098618816279.

31. Ameade EPK, Baba MM, Iddrisu NU, Musah AA, Gbedema SY. Herbal pharmacovigilance: are Ghanaian herbal medicine practitioners equipped enough to assist in monitoring the safety of herbal medicines? - a survey in Tamale, Ghana. Chronicles of Complementary, Alternative \& Integrative Medicine. 2018;1:1-10. 